\title{
Effect of Unripe Banana Flour Incorporation in Rice Papad and Resistance Starch Content
}

Mohammed Zafar IM*, Bhatawale SP, Mehrajfatema ZM, Mirza RS, Mohammad UI and Siddiqui AN

Department of Food Science and Technology, MGM College of Food Technology, Aurangabad (MS) India

\begin{abstract}
This work was conducted to improve the level of resistant starch (RS) in a rice papad using unripe banana flour and to investigate the effect of substitution of unripe banana flour for rice flour on the texture of papad dough and characteristics of papad. While preparing rice papad, the rice flour was replaced with unripe banana flour with different degrees of substitutions including $0,20,40,60,80$, and $100 \%$. The results indicated that substitution of unripe banana flour significantly affected the hardness and stickiness properties of papad dough. It was found that the papad prepared from $100 \%$ unripe banana flour indicated the greatest changes on the textural properties and $L^{*}$ value. It also showed that the highest value of sensory score was observed for 75:25 rice: banana flour. The RS value also increases with the degree of substitution.
\end{abstract}

Keywords: Banana flour; Papad; Rice papad

\section{Introduction}

Banana (Musa paradisiaca L.) is a fast growing and high biomassyielding crop in the tropical and sub-tropical regions of the world. The fruit is either consumed ripe, due to its high sugar content, or unripe, in several indigenous dishes requiring high starch content. India is the largest producer of banana next to mango. The major banana producing states are Maharashtra, Kerala, Tamil Nadu, Gujarat, Bihar, West Bengal, Assam, Andhra Pradesh and Karnataka. They are cultivated primarily for their fruit, and to a lesser extent to make fiber and as ornamental plants. The fruit averages 125 grams $(0.28 \mathrm{lb})$, of which approximately $75 \%$ is water and $25 \%$ dry matter. About $90 \%$ of banana produced is consumed domestically as fresh fruit. Merely 5\% is consumed in processed form providing a good potential for future processing. About $2.5 \%$ is only processed purely as banana products and the rest as an ingredient in other foods. The primary product of banana in market is "fried chips and candy" which constitute around $31 \%$, rest as banana puree $9 \%$, banana pulp 3\%, banana beer $3 \%$, banana wafers $3 \%$, banana powder $6 \%$ and others [1].

One of the current tendencies in nutrition and health is to consume low-carbohydrate food products. In the 1980s, dietary fiber was identified as an important component of a healthy diet, and the food industry looked for palatable ways to increase the fiber content of their products. RS, by definition, is a fraction of the starch that is not broken down by enzymes in the small intestine of human. It is then enters the large intestine where it is partially or wholly fermented by microorganism. RS is generally considered to be one of the components that make up total dietary fiber (TDF). However, it should be kept in mind that the starch source may play an important role in the nutritional and functional properties of RS products. In this sense, the nutritional/nutraceutical potential of banana starch has been claimed by several author [2,3]. Several studies have suggested that consumption of unripe bananas confers beneficial effects for human health, a fact often associated with its high resistant starch (RS) content, which ranges between $47 \%$ and 57\% [4]. Additionally, unripe banana flour might be an important source of polyphenols, compounds that are regarded as natural antioxidants [5]. Resistant starch-rich powder (RSRP) was prepared from lintnerized banana starch, which retains its amylolysis resistant features after subsequent heat treatment [6].
Papad is an oriental snack food made from dough consisting mainly of legumes such as black gram, green gram etc. along with salt and spice powders. In addition to legume based products, papads are also made from tapioca, sago, jackfruit, gelatinized rice flour and wheat flour [7]. It is prepared by rolling dough into a circular shape of $0.3-$ $2.0 \mathrm{~mm}$ thick and drying to a moisture level of $14-15 \%$. Papads have crunchy wafer-like taste, and are normally consumed after roasting or frying as an adjunct to the full meal. Most of the Indian traditional food adjuncts are made by deep fat frying [8]. During banana chips processing, lots of edible waste is generated which contains banana starch, hence an attempt was taken out to utilize this edible waste in banana papad processing.

\section{Materials and Methods}

\section{Materials}

Common salt, palm oil, unripe banana, rice were purchased from a local market of Aurangabad city. All the other chemicals used for the analysis were of analytical grade.

\section{Banana and rice flour preparation}

Commercial unripe bananas (Grand Naine) were purchased from the local market in Aurangabad, India. Fruits were peeled and cut into $1 \mathrm{~cm}$ slices and immediately rinsed in citric acid solution $(0.3 \% \mathrm{w} / \mathrm{v})$. The slices were dried at $50^{\circ} \mathrm{C}$, ground using a commercial grinder to pass a US $50(0.028 \mathrm{~mm})$ sieve and stored at $25^{\circ} \mathrm{C}$ in sealed plastic containers prior to further use. Kolum rice was obtained from local market, ground using a commercial grinder to pass a US $50(0.028 \mathrm{~mm})$ sieve and stored at $25^{\circ} \mathrm{C}$ in sealed plastic containers prior to further use.

*Corresponding author: Mohammed Zafar IM, Department of Food Science and Technology, MGM College of Food Technology, Aurangabad (MS) India, E-mail indianbanda@gmail.com

Received April 07, 2012; Accepted July 24, 2012; Published July 28, 2012

Citation: Mohammed Zafar IM, Bhatawale SP, Mehrajfatema ZM, Mirza RS, Mohammad UI, et al. (2012) Effect of Unripe Banana Flour Incorporation in Rice Papad and Resistance Starch Content. J Food Process Technol 3:169. doi:10.4172/21577110.1000169

Copyright: (C) 2012 Mohammed Zafar IM, et al. This is an open-access article distributed under the terms of the Creative Commons Attribution License, which permits unrestricted use, distribution, and reproduction in any medium, provided the original author and source are credited. 
Citation: Mohammed Zafar IM, Bhatawale SP, Mehrajfatema ZM, Mirza RS, Mohammad UI, et al. (2012) Effect of Unripe Banana Flour Incorporation in Rice Papad and Resistance Starch Content. J Food Process Technol 3:169. doi:10.4172/2157-7110.1000169

\section{Preparation of papad}

Rice flour (100 g), rice flour: banana powder (75:25), rice flour: banana powder (50:50), rice flour: banana powder (25:75), of various trials were taken and mixed thoroughly with $42 \mathrm{ml}$ of warm water containing $2 \%$ salt on flour weight basis. The mixture was kneaded for $5 \mathrm{~min}$ to form dough. Then it was passed through a papad making machine. The papads of 5-6 g each, with flat rectangular shape having $8 \mathrm{~cm}$ length and $4.5 \mathrm{~cm}$ width and $0.3-0.5 \mathrm{~mm}$ thickness were prepared by using papad making machine. The papads were dried in a tray drier at $50^{\circ} \mathrm{C}$ to a moisture level of about $14 \%$ and packed in polyethylene bags. The papads were fried for $4-5 \mathrm{~s}$ in groundnut oil at $180^{\circ} \mathrm{C}$.

\section{Texture of dough}

Hardness and stickiness of the dough was measured by using TA.XT2 Texture Analyzer' (Stable Micro Systems, Surrey, England). Dough samples were placed on the blank plate. A plate having one hole of $\sim 1 \mathrm{~cm}$ diameter was then placed on top of the sample. This plate provides weight around the test region to prevent lifting of the sample when the probe is withdrawn, hence avoiding inaccuracies in the results. The probe penetration test was then commenced. TA-XT2 settings used for evaluation of dough texture was carried out by using a $4 \mathrm{~mm}$ cylinder probe (P4) using a $5 \mathrm{~kg}$ load cell with test speed of 1 $\mathrm{mm} / \mathrm{s}$ up to a distance of $2 \mathrm{~mm}$, using a trigger force of $5 \mathrm{~g}$, and a posttest speed of $10 \mathrm{~mm} / \mathrm{s}$.

\section{Moisture content of the papad samples}

Moisture content in papads after frying was determined by drying in a hot air oven at $100^{\circ} \mathrm{C}$ to constant weight.

\section{Oil content of banana papad}

The oil content of the banana papad was determined using the Soxtec System HT extraction unit (Pertorp, Inc., Silver Spring, MD) with petroleum ether in triplicates [9]. Three grams of ground banana were weighed (Wi), placed on a cellulose extraction thimble (model 2800256, Whatman, England), and covered with a cotton ball. Six extractions in a period of $30 \mathrm{~min}$ were performed on each fried samples withdrawn at various frying times. The cup weight (W1) was recorded and $50 \mathrm{ml}$ of petroleum ether was added to each cup. The samples were then subjected to extraction, and the oil from the papads collected. Petroleum ether was evaporated by setting the unit to the "evaporation" position. To make sure all the petroleum ether was evaporated, the cups were dried in a convection oven for $20 \mathrm{~min}$ at $105^{\circ} \mathrm{C}$. The cups were then cooled in a desiccator for $20 \mathrm{~min}$, and the final cup weight was recorded (W2). Finally, the oil content (OC) was found by the relationship:

$$
\mathrm{OC}=\frac{\mathrm{W} 2-\mathrm{W} 1}{\mathrm{Wi}} \mathrm{X} 100
$$

\section{Colour of the banana papad}

The colour of the banana papad was measured using a Hunter Lab Colorimeter Labscan XE (Hunter Associates Laboratory, Reston, VA). The Hunter Lab notation was used, where $L$ denotes levels of lightness or darkness ( 0 for black, 100 for white), $a$ represents redness (positive values) or greenness (negative values), and $b$ yellowness (positive values) or blueness (negative values). Ten individual pieces of banana papads from each combination were ground separately and evaluated. The colorimeter was calibrated using a white and a black plate, and same background was used for all analysis.

\section{Texture of banana papad}

The texture of the banana papad was determined by a rupture test to determine the maximum force at compression, which is defined as "hardness". The equipment used was the TA-XT2 Texture Analyzer (Texture Technologies Corporation, Scardale, NY). This test consisted of applying a force to a banana chip by using $2 \mathrm{~mm}$ cylindrical probe at $0.1 \mathrm{~mm} / \mathrm{s}$. Hardness was measured after withdrawing the samples during various stages of frying. However, if the samples were not brittle enough, the texture values were discarded. Twenty individual pieces of banana papad were analyzed each time.

\section{Sensory analysis of the samples}

Prepared papads were subjected to sensory analysis based on 9-point hedonic scale for appearance, texture, flavour, taste and overall acceptability using a panel of 10 members who were familiar with the product since childhood. Panel members were advised to use verbal descriptions and convert them into scores. The scores were based on the following criteria: Like extremely: 9; Like moderately: 7-8; like slightly: 5-6; dislike slightly: 3-4; and dislike extremely: $0-2$. The scores were averaged and rounded to the nearest whole number.

\section{Resistant starch determination}

The resistant starch (RS) was measured according to the AOAC Method 2002.02 [10], since this method is considered the most reproducible and repeatable measurement of RS in starch [11].

\section{Data analysis}

Differences among frying trials were detected with the NCSS software (version 12.0.1 for Windows, 2003) using Duncan's multiple range tests. Statistical significance was expressed at the $\mathrm{P}<0.05$ level.

\section{Results and Discussion}

\section{Effect of banana flour on dough hardness and stickiness}

Banana flour obtained and the rice flour used for processing of papads contain $43.81 \pm 0.25$ and $1.87 \pm 0.57 \%$ resistant starch respectively. Table 1 documents the effect of addition of banana flour on hardness and stickiness of rice flour dough. It was observed that hardness of dough decreased significantly with increasing banana flour concentration $(P=0.05)$. Stickiness of dough however increased with an increase in banana flour concentration in the dough. This may be due to the water holding capacity of banana starch. Tiboonbun et al. [12] studied the effect of unripe banana flour on physical properties and resistant starch content of rice noodle and observed that the substitution of unripe banana flour significantly affected the viscosity properties of noodle flour.

\section{Effect of banana flour on rice papad characteristics}

From (Table 2) it can be observed that no significant effect was

\begin{tabular}{|c|c|c|c|}
\hline Sr. No. & $\begin{array}{c}\text { Rice: banana flour } \\
\text { papad samples }\end{array}$ & Hardness, g & Stickiness, g \\
\hline 1 & $100: 00$ & $565.55 \pm 12.26^{\mathrm{a}}$ & $70.78 \pm 2.65^{\mathrm{a}}$ \\
\hline 2 & $75: 25$ & $327.07 \pm 17.52^{\mathrm{b}}$ & $82.12 \pm 3.43^{\mathrm{b}}$ \\
\hline 3 & $50: 50$ & $303.58 \pm 10.25^{\mathrm{c}}$ & $100.42 \pm 4.89^{\mathrm{c}}$ \\
\hline 4 & $25: 75$ & $262.39 \pm 12.10^{\mathrm{d}}$ & $122.45 \pm 3.89^{\mathrm{d}}$ \\
\hline 5 & $00: 100$ & $231.64 \pm 21.26^{\mathrm{e}}$ & $136.55 \pm 4.06^{\mathrm{e}}$ \\
\hline
\end{tabular}

Values in the same column with different letters are significantly different $(P=0.05)$ as measured by Duncan's multiple-comparison test.

a Values are mean \pm SD of three or more determinations.

Table 1: Effect of banana flour addition on rice papad dough characteristics. 
Citation: Mohammed Zafar IM, Bhatawale SP, Mehrajfatema ZM, Mirza RS, Mohammad UI, et al. (2012) Effect of Unripe Banana Flour Incorporation in Rice Papad and Resistance Starch Content. J Food Process Technol 3:169. doi:10.4172/2157-7110.1000169

Page 3 of 3

\begin{tabular}{|c|c|c|c|c|c|c|c|}
\hline Sr.No. & $\begin{array}{l}\text { Rice: banana flour } \\
\text { papad samples }\end{array}$ & $\begin{array}{c}\text { Moisture } \\
\text { content (\%) }\end{array}$ & $\begin{array}{l}\text { Oil content } \\
(\%)\end{array}$ & Texture, $\mathbf{g}$ & Color value $\mathrm{L}^{*}$ & Sensory score & $\begin{array}{c}\text { Resistant Starch } \\
(\%)\end{array}$ \\
\hline 1 & $100: 00$ & $4.18 \pm 0.02^{\mathrm{a}}$ & $26.85 \pm 0.03^{a}$ & $52.2 \pm 2.02^{\mathrm{a}}$ & $82.24 \pm 0.02^{\mathrm{a}}$ & 9 & $7.54 \pm 0.02^{\mathrm{a}}$ \\
\hline 2 & $75: 25$ & $4.02 \pm 0.04^{\mathrm{a}}$ & $25.12 \pm 0.04^{b}$ & $53.76 \pm 3.02^{\mathrm{a}}$ & $77.58 \pm 0.01^{\mathrm{b}}$ & 9 & $9.12 \pm 0.05^{b}$ \\
\hline 3 & $50: 50$ & $4.20 \pm 0.03^{b}$ & $24.16 \pm 0.05^{c}$ & $57.10 \pm 1.02^{b}$ & $65.54 \pm 1.07^{c}$ & 8 & $10.15 \pm 0.04^{c}$ \\
\hline 4 & $25: 75$ & $4.21 \pm 0.07^{b}$ & $22.22 \pm 0.05^{c}$ & $59.74 \pm 2.07^{b}$ & $63.28 \pm 0.55^{d}$ & 7 & $12.02 \pm 0.03^{d}$ \\
\hline 5 & $00: 100$ & $4.16 \pm 0.04^{a}$ & $21.01 \pm 0.10^{d}$ & $60.15 \pm 1.02^{b}$ & $59.17 \pm 0.10^{e}$ & 6 & $13.65 \pm 0.03^{e}$ \\
\hline
\end{tabular}

Values in the same column with different letters are significantly different $(P=0.05)$ as measured by Duncan's multiple-comparison test.

Values are mean \pm SD of three or more determinations.

'Oil content is expressed on moisture-free basis.

Table 2: Effect of banana flour addition on rice papad characteristics.

observed on moisture content of fried papad, whereas significant effect was observed on percent oil content for all blends [13]. We have standardized the process for papad preparation from cooked unripe banana pulp and rice flake flour mix and observed that the blend containing 40 parts of rice flakes flour and 60 parts of cooked banana pulp on dry weight basis yielded papads with acceptable colour, texture, flavour upon deep fat frying. We also studied the effect of incorporation of various ingredients namely nalleru (Cissus quadrangularis), gum karaya (Sterculia urens) and soya flour on diametrical expansion and oil absorption of papads [14]. They observed that the diametrical expansion and oil absorption did not show any major changes with the addition of Cissus extract. The addition of soya flour reduced the oil absorption. Gum karaya helped in retaining the dough's moisture, which in turn resulted in increased diametrical expansion on deep fat frying.

From (Table 2) it can be also observed that the texture value i.e., hardness value increased significantly as the banana flour concentration was increased from 0 to 100 . It is also observed that the colour value $\mathrm{L}^{*}$ decreases significantly with increase in concentration of banana flour. Tiboonbun et al. [12] prepared rice noodle using unripe banana flour with different degrees of substitutions including $0,20,40,60,80$, and $100 \%$. They observed a significant decrease in $\mathrm{L}^{\star}$ values $(\mathrm{p} \leq 0.05)$ with increase in banana flour proportion. The highest $L^{*}$ values was found in rice noodle prepared from $0 \%$ of banana flour or $100 \%$ of rice flour and gradually decreased in noodle replaced with $20 \%, 40 \%, 60 \%, 80 \%$ and $100 \%$ of banana flour. The decrease in sensory score is observed in Table 2, which may be due to increase in hardness and decrease in $\mathrm{L}^{\star}$ value of papads with the increase in concentration of banana flour.

An increase in RS content was observed in rice papad substituted with unripe banana flour (Table 2). The papad containing $0 \%$ of unripe banana flour indicated lowest amount of RS (7.54\%), whilst the rice papad containing $100 \%$ of unripe banana flour had significantly highest content of RS (13.65\%). This is related to the high RS content of banana flour; the obtained results are in good agreement with that of Tiboonbun et al. [12].

\section{Conclusion}

The replacement of unripe banana flour for rice flour significantly affected the hardness, oil content and RS content of rice papad. Increasing the degrees of substitution by unripe banana flour improves the dough properties. The replacement of unripe banana flour for rice flour could be applied to improve the RS content and oil content of rice papad. Higher the degree of substitution, higher the level of RS content and lower the level of oil content. However, when the degree of replacement of unripe banana flour was greater than $50 \%$, it adversely affected the $L^{*}$ value i.e., whiteness of papad hence overall acceptability as well as texture also gets affected. Therefore, the optimization of several factors affecting the overall quality of rice papad, incorporated with unripe banana flour, is important to obtain the best possible dough and sensory quality of rice papad, as well as to achieve health benefits of the high RS rice papad.

\section{References}

1. Rashmi SB, Jyothsna V (2011) Rural entrepreneurship: exploring the opportunities from waste products of bananas plant in Karnataka. International Journal of Research in Computer Application \& Management 1: 105-107.

2. Englyst HN, Kingman SM, Cummings JH (1992) Classification and measurement of nutritionally important starch fractions. Eur J Clin Nutr 46: 3350 .

3. Pacheco-Delahaye E, Perez R, Schnell M (2004) Nutritional and sensory evaluation of powder drinks based on papaya, green plantain and rice bran. Glycemic index. Interciencia 29: 46-51.

4. Faisant N, Gallant DJ, Bouchet B, Champ M (1995) Banana starch breakdown in the human small intestine studied by electron microscopy. Eur $\mathrm{J}$ Clin Nutr 49: 98-104.

5. Vergara-Valencia N, Granados-Pereza E, Agama-Acevedo E, Tovar J, Ruales $\mathrm{J}$, et al. (2007) Fibre concentrate from mango fruit: Characterization, associated antioxidant capacity and application as a bakery product ingredient. Lebenson Wiss Technol 40: 722-729.

6. Aparicio-Saguilán A, Flores-Huicochea E, Tovar J, García-Suárez F, GutierrezMeraz F, et al. (2005) Resistant starch-rich powders prepared by autoclaving of native and lintnerized banana starch: partial characterization. Starch 57: 405412

7. Arya SS (1990) Grain based snack and convenience foods. Indian Food Packer 44: 17-38.

8. Pushpamma P, Geervani P (1981) Nutritive value of traditional recipes of Andhra Pradesh. Andhra Pradesh Agriculture University, Hyderabad, India.

9. AACC (1986) Approved methods of the american association of cereal chemists. Minneapolis, MN: AACC

10. McClearly BV, Moanghan DA (2002) Measurement of resistant starch. J AOAC Int 85: 665-675.

11. Champ M, Langkilde AM, Brouns F, Kettlitz B, Bail-Collet YL (2003) Advances in dietary fiber characterization.2. Consumption, chemistry, physiology and measurement of resistant starch; implications for health and food labeling. Nutr Res Rev 16: 143-161.

12. Tiboonbun W, Sungsri-in M, Moongngarm A (2011) Effect of replacement of unripe banana flour for rice flour on physical properties and resistant starch content of rice noodle. World Academy of Science, Engineering and Technology 81.

13. Kulkarni SG, Manan JK, Shukla IC (1992) Preparation, evaluation and storage of papads made from rice flakes (poha) flour and unripe banana. Beverage and Food World 13-18.

14. Velu V, Balaswamy K, Nagender A, Rao DG (2004) Effect of various ingredients and additives on papads. Foodservice Research International 15: 78-88. 